\title{
THE OCCURRENCE OF 'END-TO-END' FUSION BETWEEN ADJACENT CHORIOALLANTOIC SACS IN THE EARLY PIG EMBRYO
}

\author{
PAULA RAQUEL GROMBIE \\ A.R.C. Institute of Animal Physiology, \\ Babraham, Cambridge
}

(Received 30th September 1971, accepted 10th November 1971)

In 1922, Corner described three cases of monochorionic twinning in pigs between the 2nd and 4th weeks of gestation. He proposed that these specimens were actually examples of twins arising within a single conceptus. $\mathrm{He}$ considered the alternative possibility that each of these three specimens could have arisen by fusion of two originally separate blastocysts unlikely because of the failure to find other and more numerous examples of less deceptively perfect fusions. Further, he stated that such fusion was uncommon in the early stages of development in the pig. However, Hughes $(1927,1929)$ reported the occurrence of fusion between adjacent chorioallantoic sacs in older pig fetuses (40 to 51 days of pregnancy). She demonstrated that, when there was vascular continuity between the fused sacs of embryos of opposite sex, the female could be modified into a freemartin. More recently, Ashdown \& Marrable (1967, 1970) described the ischaemic zones of the chorioallantois and stated that ischaemic changes precede the processes of adhesion and fusion between adjacent sacs. Since ischaemic changes are first observed around the 5th week of pregnancy, this would place the development of fusion somewhere towards the end of the first third of the period of gestation, at the earliest. They also state that, 'The sequence of interlocking and adhesion between ischaemic zones, adhesion between paraplacental zones and histological fusion between placental zones progresses in the last two-thirds of pregnancy' (Ashdown \& Marrable, 1970).

Because of these opposing points of view concerning the time and mode of development of the monochorionic condition, it was of interest to find an example of fusion between the chorionic membranes of two early pig conceptuses. Histological evidence of fusion and a description of the arrangement of the fetal membranes is presented here.

The material was taken from a gilt on the 22nd day of pregnancy, well within the first third of the period of gestation. The extreme tips of the two chorioallantoic sacs were intimately fused and could not be separated (Pl. 1, Fig. 1). At this stage of pregnancy, vascularization of the chorion is incomplete and does not extend to the ends of the sac. Text-figure 1 illustrates diagrammatically the manner in which the sacs overlapped and fused.

The chorioallantoic sacs were fusiform and as yet undifferentiated into ischaemic extremities and central placental zones. The allantoic sac seen to the 
left of Pl. 1, Fig. 1, with the overlying chorion removed, was itself only poorly vascularized but its surface was still healthy, as was that of the chorion. The area of fusion is indicated by arrows.

The histological section seen in Pl. 1, Fig. 2 shows the relationship of the chorion and allantois and the fused areas. The allantois occupies the innermost position, and is largely free from the overlying chorion; attachment of these two layers is not completed until the 4th week of gestation. External to these layers is a region of chorioallantois. Plate 2, Fig. 3 shows the membranes at a higher magnification; the allantoic cavity lies to the left, the 'extra' layer of allantois seen to the extreme left is due to the membrane being folded back on itself. The fused chorions lie to the right of the allantois; this is the true region of fusion between the two overlapping chorioallantoic sacs. On the extreme right, the allantois lies between the fused chorions and the outermost chorioallantoic membrane, from which it is separated by a very narrow allantoic cavity. The fused chorions are shown at higher magnification in PI. 2, Fig. 4; their epithelial layers lie in close apposition to each other, but they are initially intact.

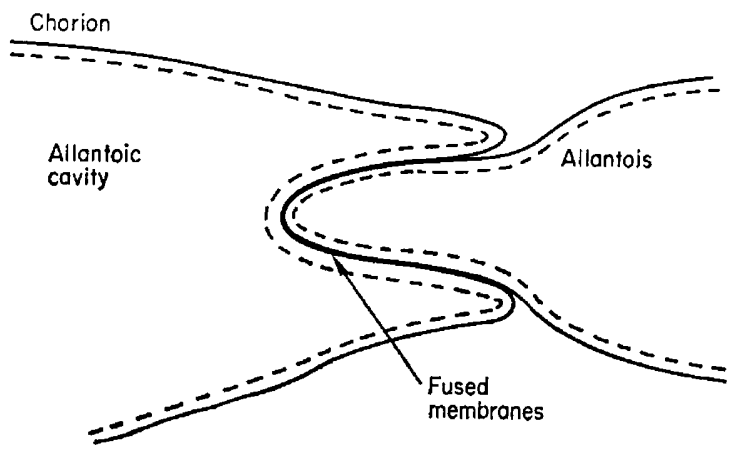

TEXT-FIG. 1. Diagram showing the relationship of the two chorionic sacs; the region of fusion is indicated. Side view.

This pattern of two closely apposed, yet separate epithelial layers is lost as the chorions begin to fuse. The ordered arrangement breaks down as the cell boundaries'degenerate and the cells become grouped into irregular, disorganized aggregates (Pl. 2, Fig. 5). Ultimately, the progressive disruption of cellular integrity results in the total disappearance of the intervening epithelial layers so that the connective tissue stromata are in direct continuity.

Areas in which chorioallantoic and chorionic membranes were beginning to adhere and, where they would presumably have fused, were also found (Pl. 2, Fig. 6). This appears to be a very early stage since the epithelia were still separated by an intervening layer of uterine secretion.

A study of the serial sections failed to reveal the development of any vascular anastomoses, a finding in keeping with Hughes' comment on the infrequence of such an occurrence in cases of end-to-end fusion. In cases of side-to-side fusion, however, vascular anastomoses are more readily developed (Hughes, 1927, 1929).

This examination of the fused membranes supports Hughes' assertion that fusions resulting in this monochorionic twinning condition must develop early 


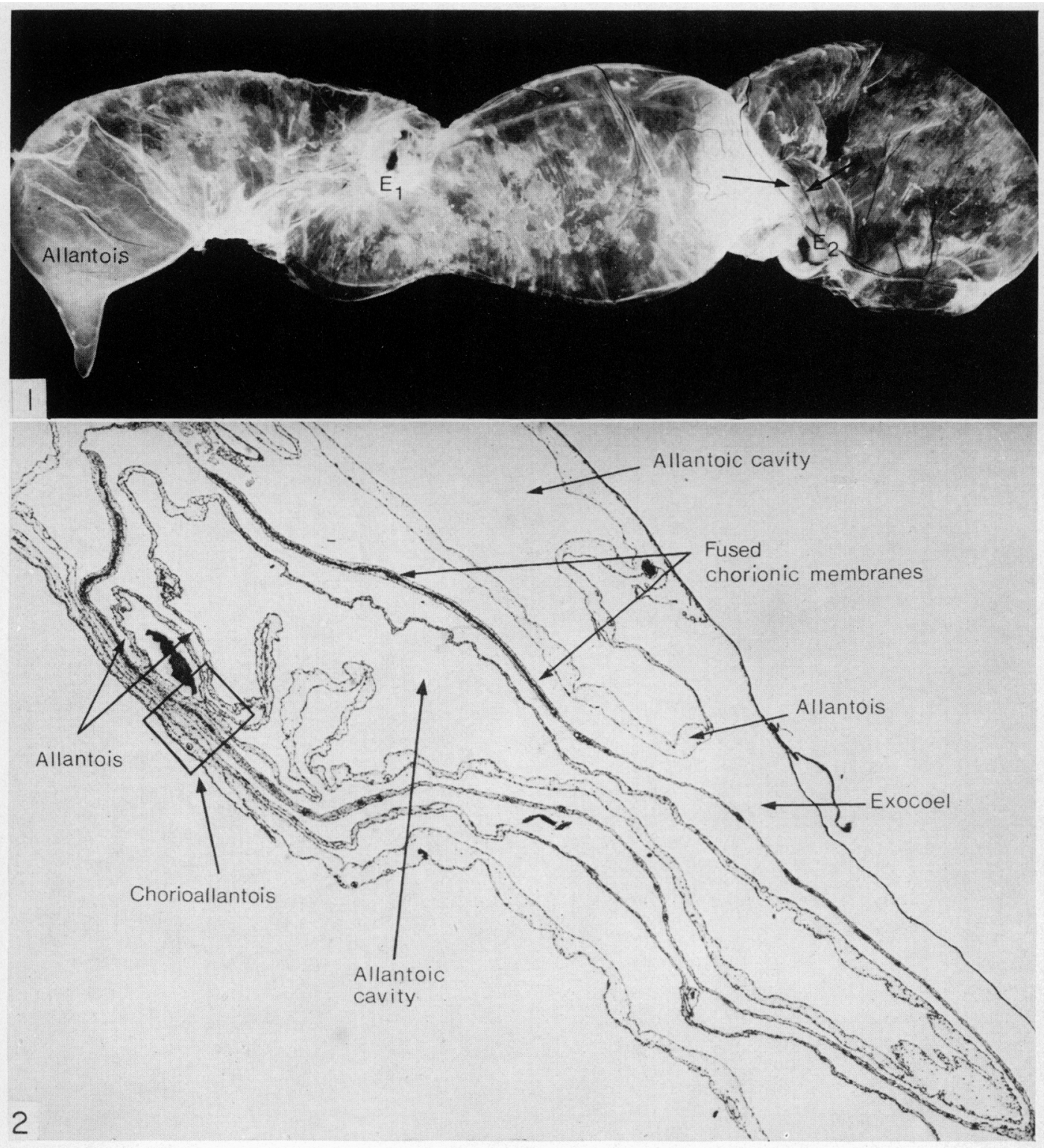

FIG. 1. Day-22 embryonic sacs fused together over their extremities (arrows). The position of the respective embryos is indicated $\left(\mathrm{E}_{1}\right.$ and $\left.\mathrm{E}_{2}\right) . \times \frac{1}{2}$.

Frg. 2. Low power plan of the membranes in section, illustrating their spatial relationships. $\times 27$. 
PLATE 2
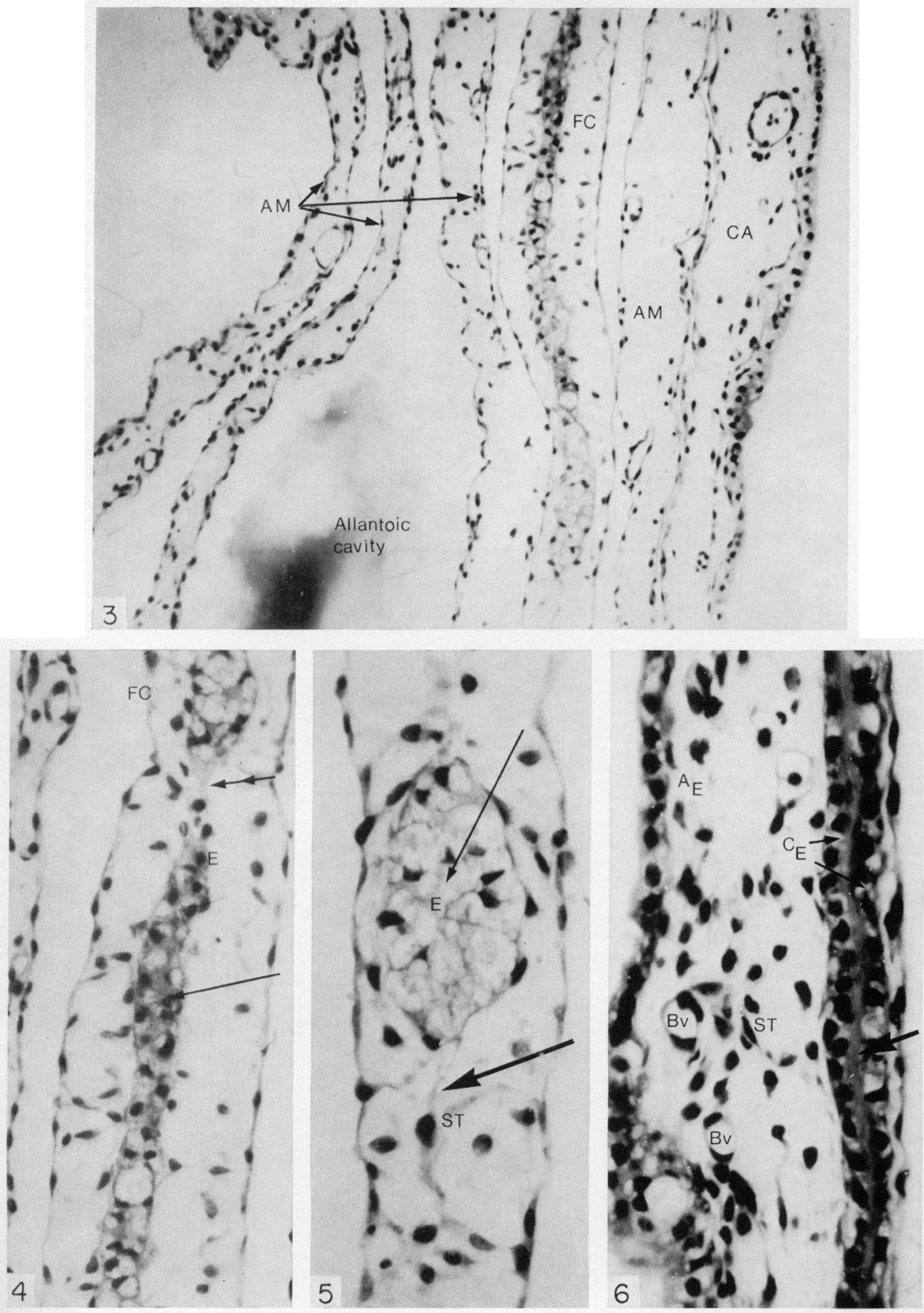
in embryonic life. The extensive overlapping and invagination of adjacent necrotic chorionic sacs which Corner (1922) described occurred without the establishment of true fusions (Hughes, 1929), which produces the monochorionic twinning condition.

The confirmation of Hughes' claim would seem to suggest that the 'fusions' reported and described by Ashdown \& Marrable (1967) are not the same type as the fusions which develop early in pregnancy. Their statement that it was easy to separate the fused late-pregnancy chorioallantoic sacs suggests that normally there is only adhesion between the extremities without any morphological fusion. The fused sacs described in this report could not by any means be separated into their original pre-fusion components.

I wish to acknowledge the advice and assistance of Dr J. S. Perry, and the financial support of the Meat and Livestock Commission from whom I received a Post-Graduate Scholarship.

\section{REFERENCES}

Ashdown, R. R. \& Marrable, A. W. (1967) Adherence and fusion between the extremities of the adjacent embryonic sacs in the pig. F. Anat. 101, 269.

Ashdown, R. R. \& Marrable, A. W. (1970) Development of the foetal membranes of the pig: observations on the afterbirths. Res. vet. Sci. 11, 227.

Corner, G. W. (1922) The morphological theory of monochorionic twins as illustrated by a series of supposed early twin embryos in the pig. Johns Hopkins Hosp. Bull. 33, 389.

Hughes, W. (1927) Sex intergrades in foetal pigs. Biol. Bull. mar. biol. Lab. Woods Hole, 52, 121.

Hughes, W. (1929) The freemartin condition in swine. Anat. Rec. 41, 213.

\section{EXPLANATION OF PLATE 2}

FIG. 3. The area enclosed in the rectangle in Fig. 2 enlarged. (AM, allantoic membranes; CA, chorioallantois; FG, fused chorions). $\times 184$.

Fig. 4. The fused chorions (FC). The epithelial layers (E) initially lie in close contact to each other (long arrow), but subsequently their separate identity is lost as the cellular layers degenerate and disappear (double-headed arrow). $\times 390$.

FIg. 5. A late stage in disintegration of the epithelial layers. The epithelial cells (E) indicated by the small arrow have lost their separate identity and ordered alignment within the original cell layers. In other areas (large arrow), the cells have disappeared altogether, leaving the two connective tissue stromata (ST) in direct continuity. $\times 520$.

FIg. 6. An area of close approximation between chorionic and chorioallantoic layers; the respective chorionic epithelia $\left(\mathrm{C}_{\mathrm{E}}\right)$ are separated by an intervening layer of mucus $\left(\right.$ arrow). $\left(\mathrm{A}_{\mathrm{E}}\right)$ allantoic endoderm; $(\mathrm{Bv})$ blood vessel. $\times 570$. 